\title{
Social Issue-Oriented BoP Business and Japanese Companies
}

\author{
Case Study: Sumitomo Chemical's Olyset Nets \\ Instilling the "Sumitomo Spirit"
}

\section{BY MARI KOGISO, MIA MATSUO AND TOKUTARO HIRAMOTO}

THE SUMITOMO GROUP requires all of its member companies and business operations to work under a business management philosophy called the "Sumitomo Spirit," which aims to generate profits not only for the company, but also for society. One of Sumitomo Chemical Co., Ltd.'s businesses involves the production of insecticide-treated mosquito nets.
- All employees-from the management and technical staff to those at Group companies-have lobbied international aid organizations in promotion of the Olyset Nets project, convinced that the mosquito net could become an indispensable tool in the prevention of malaria outbreaks.

From 1993 to 2001, the staff of Sumitomo and its Group companies worked tirelessly through trial and error to develop the modern Olyset Nets, which are certified by the World - Health Organization (WHO) as Long-Lasting Insecticidal Nets

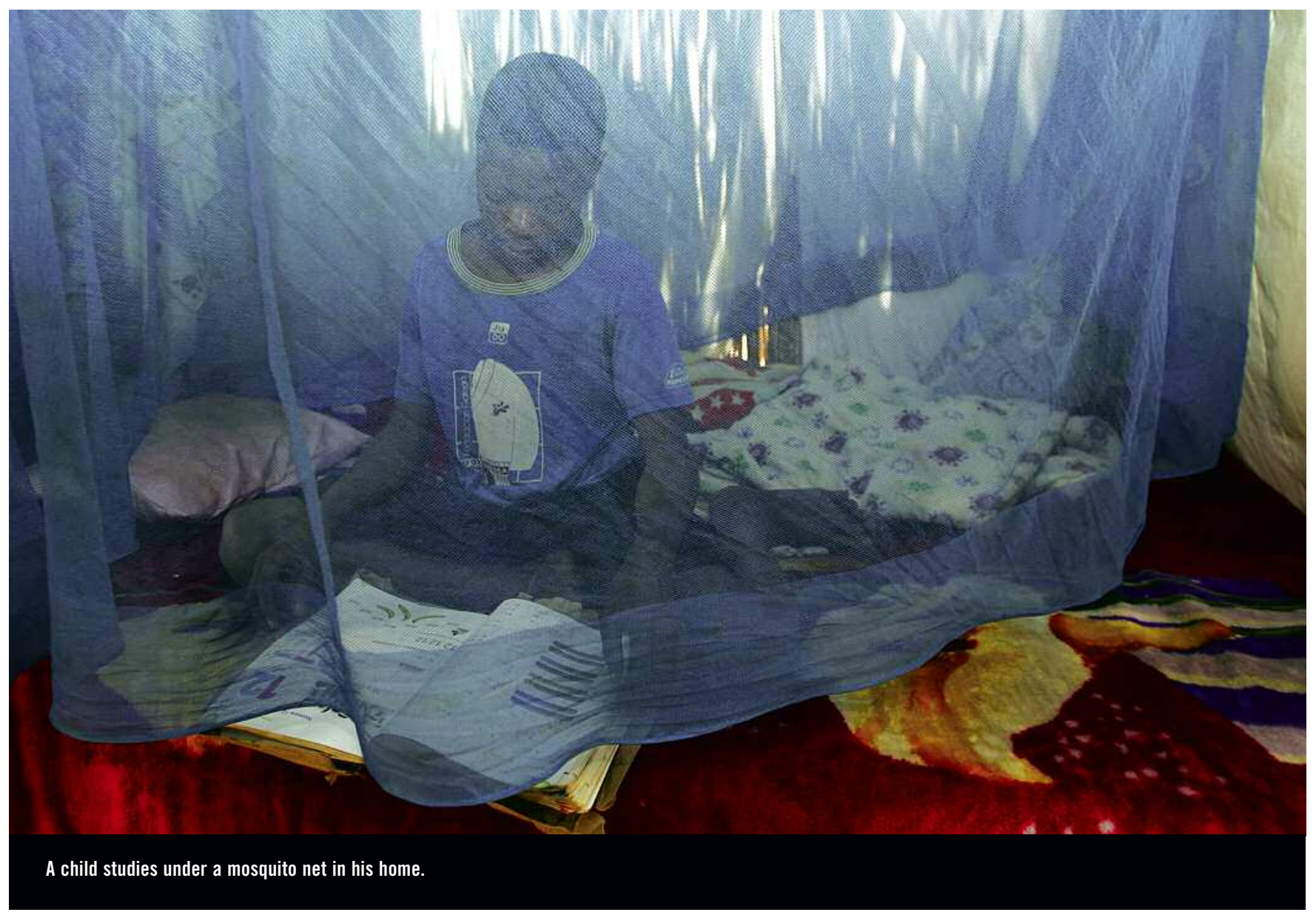


(LLIN). The prototype insect-resistant net was originally developed to prevent insects from penetrating the manufacturing processes at factories. Since the nets needed to be durable for use in factory environments, polyethylene was used instead of polyester, making the original nets high quality but very costly to produce. Initially, demand for the product was not strong, so Sumitomo developed a technology to treat the polyethylene resins used on the netting material with an insect-expelling agent, eventually leading to the development of the current Olyset Nets.

Despite this, the Olyset Net business did not generate the intended results in terms of profitability, and efforts made by the marketing staff at Group companies in Africa gave disappointing results, as only small numbers of the product were sold. Despite this initial setback, Sumitomo continued to promote the business, convinced that it would become successful at some point in the future. This situation continued until the product was officially certified in 2001 by the WHO as having long-lasting insecticidal effects, which contributed to the present success of the product.

\section{The development of Olyset Nets- designing the optimal approach for users with critical needs}

THE SUCGESS OF THE OLYSET NET business is due mostly to the nets' high quality and easy-to-handle form, especially among households with small children in developing countries. The creation of the product would not have been possible without the long term support from the company's corporate philosophy, which enables it to allocate a fixed ratio of its sales profits on investments in research and development.

Sumitomo's Olyset Net turned out to be a product capable of solving the problems associated with conventional mosquito nets since the insecticidal efficacy of the chemical agents

\section{TABLE 1: OVERVIEW OF OLYSET NET BUSINESS}

\begin{tabular}{|c|c|c|c|c|}
\hline YEAR & TECHNOLOGY & PRODUCTION & SALES & OTHERS \\
\hline 1993 & $\begin{array}{l}\text { Launched into insect-resistant } \\
\text { net development project }\end{array}$ & & & \\
\hline 2001 & $\begin{array}{l}\text { Approval by WHO as "Long-Lasting } \\
\text { Insecticidal Nets (LLN)" }\end{array}$ & $\begin{array}{l}\text { Established 1st Project team } \\
\text { with Acumen Fund }\end{array}$ & & \\
\hline 2002 & & Production start in Changzhou, China & Sales start in Africa & \\
\hline 2003 & & $\begin{array}{l}\text { Licensing to } A \text { to } Z \text { Textile Mills Ltd. } \\
\text { and production start in Tanzania }\end{array}$ & & \\
\hline 2004 & $\begin{array}{l}\text { Olyset Net wins Time's "Most } \\
\text { Amazing Invention" }\end{array}$ & & & \\
\hline 2005 & & Production start in Dalian, China & & \\
\hline 2006 & $\begin{array}{l}\text { Olyset Net wins "USA Tech Museum } \\
\text { Awards" }\end{array}$ & Production start in Vietnam & $\begin{array}{l}\text { Provided } 30 \text { million Olyset } \\
\text { Nets from } 2003 \text { to } 2006\end{array}$ & $\begin{array}{l}\text { Build elementary school facilities } \\
\text { and start education support programs }\end{array}$ \\
\hline 2007 & & $\begin{array}{l}\text { Established Vector Health } \\
\text { International Ltd. And production start }\end{array}$ & & $\begin{array}{l}\text { Olyset Net wins "Asahi Corporate } \\
\text { Citizenship Award" }\end{array}$ \\
\hline
\end{tabular}

\section{TABLE 2: OLYSET NET MANUFACTURING SCALE}

\begin{tabular}{|lrrrr|}
\hline & & & & \\
\hline WORLDWIDF & 2004 & 2005 & 2006 & 2007 (F) \\
\hline Capacity of production (million nets/year) & 500 & 1250 & 1800 & 3100 \\
\hline Employees in Olyset production & 1300 & 3400 & 4300 & 6800 \\
\hline Employment creation (per million nets) & 260 & 272 & 239 & 219 \\
\hline & & & & \\
\hline AFRIfA & 2004 & 2005 & 2006 & 2007 (F) \\
\hline Capacity of production (million nets/year) & 100 & 400 & 400 & 800 \\
\hline Employees in Olyset production & 350 & 1200 & 1200 & 2400 \\
\hline Employment creation (per million nets) & 350 & 300 & 300 & 300 \\
\hline
\end{tabular}

Source: Sumitomo Group
TABLE 3: OLYSET NET MANUFACTURING SCALE IN AFRICA

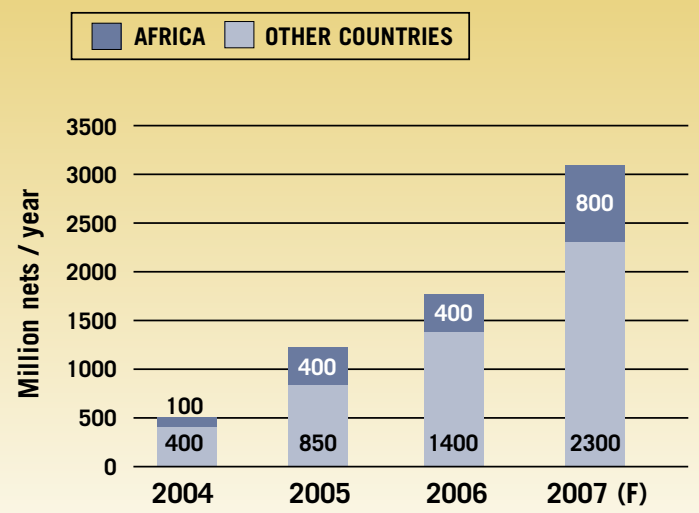

Source: Sumitomo Group 
applied to polyethylene resins in the net was guaranteed to last five years, and the insecticidal properties were also unaffected by washing. Furthermore, the use of polyethylene makes the mesh of the net resistant to stretching and tearing. With a largesized mesh, the net breathes well, a characteristic suitable for houses built in tropical areas prone to malarial outbreaks.

\section{Establishing joint ventures with local companies with support from governmental organizations: Quality control and the introduction of technology}

SUMITOMO'S OLYSET NET venture has been supported by a business environment where a private-sector company can receive financial support from government organizations when launching new business in developing countries. The Olyset Net business represents a successful case of collaboration between the public sector-the party in charge of supporting fund-raising, and the private sector-the party in charge of the project's actual business operations. Such collaborations have allowed Sumitomo to succeed in fostering local companies which can potentially take charge of the manufacturing process within the BoP market.

Sumitomo licensed its own manufacturing expertise for Olyset Nets to a local company, A to Z Textile Mills Ltd. (A to Z) in Tanzania at no charge, which led to the start of local production. According to the WHO, annual demand for LLIN amounts to 60 million to 80 million nets. To meet this demand, Sumitomo arranged loans for US\$5.8 million from the Japan Bank for International Cooperation (JBIC) to finance the initial for a joint venture, Vector Health International Ltd. (VHI), with A to Z. VHI initiated production in January 2007 with an annual output capacity of 4 million nets, and the company plans to double annual production to 8 million nets in the future. Sumitomo has emphasized its commitment to completely infusing its technology into VHI.

This manufacturing process is labor-intensive, contributing to local employment with a total of 1,200 workers. Sumitomo does not intend to secure profits by collecting licensing fees for this technology, but gives priority to expanding local production by providing education and training to local production staff. In order to help local staff acquire know-how about Olyset Nets, Sumitomo has sent its own engineers to Tanzania. At the factory, the Japanese engineers are educating local employees in production management, quality control, and worker safety. This investment in employee education is a huge effort, particularly because Sumitomo had to begin the business from scratch, a situation radically different from cases where factories are built in areas where companies can take charge of the manufacturing processes which already exist.

Sumitomo decided that it was important to dispatch its engineers to the Tanzanian company and to train local workers in production technology, control of the manufacturing process, and quality control. Technological transfer usually involves less transfer costs on the side of the party that is doing the transfer, but it is quite difficult to fully transfer its quality control know-how in the manufacturing process to the recipient company. For example, at Olyset Nets, if a hole is left in a mosquito net due to an error in the sewing, mosquitoes can penetrate the net. In view of these kinds of potential risks, educating and training local workers sufficiently in order to fully introduce the relevant technology into the manufacturing company is vital, even if it entails additional costs. In the Base of the Pyramid ( $\mathrm{BoP}$ ) market, a business is required to develop not only potential consumers but also potential producers when undertaking this kind of BoP business.

\section{The Olyset Net business and socially-oriented BoP business}

OLYSET NETS TECHNOLOGY has directly contributed to the prevention of malaria in developing countries, and profits earned through the business have been re-invested into a plan to expand local production bases, while technological introduction has been instrumental in boosting local production capacity. This has all led to increased employment. In addition, Sumitomo Chemical and the Sumitomo Group have used a part of the profits from the Olyset Nets business to finance the establishment of elementary schools in local areas. These activities are capable of nurturing potential producers and consumers on a long-term basis.

\section{Social $\mathrm{BoP}$ and Japanese business customs are compatible}

AS THE SUMITOMO EXPERIENCE demonstrates, Japanese companies are in a good position to engage in "social issueoriented BoP business" (social BoP), which is the ability of business to contribute to solving poverty and other social issues in a gradual manner by offering products and services to BoP households, while maintaining respect for their values.

Japanese companies possess three major characteristics inherently suited to this type of social BoP business:

- the ability to conduct long-term corporate management,

- the ability to make continuing and long-term investments in research and development, and

- the ability to receive support from governmental organizations and agencies.

Long-term corporate management is closely associated with Japanese business culture and the nature of Japanese stock and financial markets, which still allow Japanese companies to conduct business with a long-term view. Although the number of shareholders who are vocal about their opinions has increased in Japan and shareholder demands have become more transparent, the relative number of shareholders focused primarily on pursuing short-term profit is still lower than in the United States and Europe, making it easier for corporate managers to conduct business with a long-term vision. Under the leadership of managers with long-term views and prospects, Japanese companies are able to engage in social BoP business, working to 
resolve immediate social issues while time seeking to reap profits from their efforts in the future.

The ability to make continuing investments in research and development reflects the inclination of Japanese companies to maintain funding for technological investments, even in difficult business climates. The ratio of research-related spending in Japan in terms of its gross domestic product (GDP) has been the highest among major industrial countries since the late 1980s. (White Paper on Science and Technology, 2007). Researchrelated spending by the private sector accounts for about 80 percent of all such spending in Japan, which is higher than the ratio of this area of private-sector spending in other developed countries, suggesting that Japanese businesses are inclined to continue to invest in research and development activities even under difficult business conditions.

Japanese companies can receive financial support from governmental organizations when launching new businesses in developing countries-making it possible for companies to use funds in a manner that suits the business terms of each project. Such financial support is often through overseas investment loans by the Japan Bank for International Cooperation, whose lending scheme enables Japanese companies with an eye on investing in new businesses overseas to utilize low-interest loans on a long-term basis. It also allows them to utilize funds for investment in social BoP business projects that are expected to take a significant period of time to bear profit, since it is relatively easy for them to overcome the initial difficulty of raising funds for such businesses.

\section{Challenges to companies engaged in BoP business}

IN ORDER TO REALIZE continued success in social BoP business, Japanese companies need to address two major issues. The first challenge is the need to strengthen their networks with international organizations, nonprofit organizations (NPOs), and nongovernmental organizations (NGOs). As a rule, Japanese companies' networks with international organizations, NPOs, and NGOs are not strong. Companies need to reinforce their networks with these organizations in order to promote social BoP. In the case of Sumitomo, its Olyset Nets business in Tanzania is being efficiently implemented as a result of the company's deepening networks with an international organization. Sumitomo has also recognized that an important challenge for the company in further expanding its business is to increase its contact with customers, and naturally it is considering how to best reinforce networks with international organizations, NPOs, and NGOs.

Japanese companies also need middle managers to widen their management perspective through better in-house cooperation and avoiding organizational sectionalism. Managers should deepen their understanding about relations between relevant divisions from the viewpoint of corporate management. For example, when a company tries to form a partnership with an NGO, its department in charge of corporate social responsibility (CSR) becomes the party most likely to negoti-

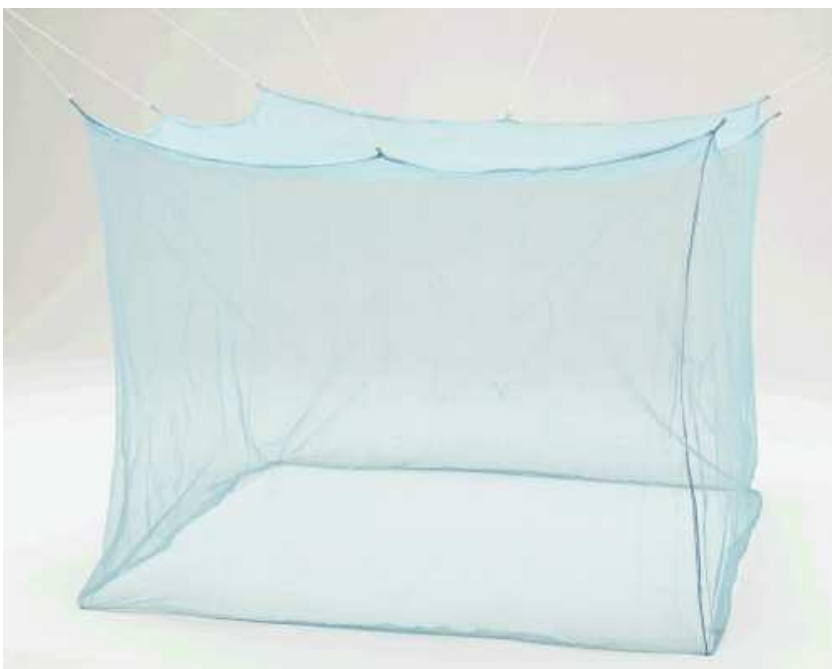

Sumitomo Chemical Olyset Net

ate, but when the company tries to resolve social issues or problems related to its business, it generally turns to employees working at an in-house research division who are believed to be knowledgeable about the issue. In Sumitomo's case, a strong commitment to inter-divisional cooperation within the company helped to make CSR activities more palatable, and other activities such as the establishment of a local school went forward as part of its BoP business.

By addressing these types of challenges, Japanese businesses will be able to engage in social BoP business smoothly and effectively, making it possible for them to resolve important social issues and also to reap the many rewards in the BoP market in the future. Now, some other Japanese companies, like Yakult Honsha and Yamaha Motor, are also expanding their businesses into the BoP markets, and it is expected that still others in the various industries will follow these trends.

Mari Kogiso is Tokyo Representative of MIGA, World Bank Group. Mia Matsuo and Tokutaro Hiramoto are with the Social Innovation Foresight Team, Nomura Research Institute, Ltd. Tokyo.

\section{References}

Ministry of Education, Culture, Sports, Science and Technology, White Paper on Science and Technology 2007, 2007.

Organization for Economic Co-operation and Development, Main Science and Technology Indicators, 2006.

Statistics Bureau, Ministry of Internal Affairs and Communications, Survey of Research and Development, 2006.

Sumitomo Chemical Co., Ltd., Sumitomo Chemical CSR Report 2006, 2007, accessible at:http://www.sumitomo-chem.co.jp/english/responsible/pdf/ 2006csr/2006csre_02.pdf.

Sumitomo Chemical Co., Ltd., SUMITOMOKAGAKU, vol. 58, 2007.

Sumitomo Chemical Co., Ltd., SUMITOMOKAGAKU, vol. 61, 2007.

World Resources Institute, The Next 4 Billion: Market Size and Business Strategy at the Base of the Pyramid, p.1-3, 2007.

\section{Endnotes}

1 White Paper on Science and Technology 2007, published by the Japanese Ministry of Education, Culture, Sports, Science and Technology. 